\title{
DA BIKE AO MIRAGE E AO HELICÓPTERO: VERGÍLIO FERREIRA E HERBERTO HELDER
}

\author{
Maria Lucia Dal Farra*
}

Se não me engano, a única vez que toquei no nome de Herberto com Vergílio foi numa carta em início de 1974, quando lhe revelei que me dedicaria então à obra do poeta da Madeira no meu futuro doutorado a ser defendido na Universidade de São Paulo ${ }^{1}$. E, de fato, em 1979, esse empenho resultaria num livro, publicado apenas em 1986 pela Imprensa Nacional/Casa da Moeda, denominado Alquimia da Linguagem (Leitura da Cosmogonia Poética de Herberto Helder). Porém, naquela altura, eu vinha de defender, na mesma USP, o meu mestrado, dissertação que tinha por título $O$ Narrador Ensimesmado (O Foco Narrativo em Vergílio Ferreira), e Óscar Lopes, através do próprio Vergílio, havia demonstrado interesse em publicá-la pela Inova. Discutíamos, na nossa correspondência, justo tal possibilidade: se o original deveria seguir para o Porto ou para São Paulo - no caso, para a Ática, onde seria deveras editado em 1978 - quando lhe dei a notícia da minha decisão de estudar a obra poética do Herberto.

Vergílio foi receptivo à minha escolha mas, como me segredava, teria preferido que, em lugar de Herberto, eu me dedicasse à poesia de António Ramos Rosa, seu muito próximo amigo. E ele me afiançava em carta de 13 de Março desse ano que, "se Herberto Helder é um grande autor, o Ramos Rosa náo o é menos - e para mim é mesmo maior (o que sem dúvida tem apenas que ver com uma questáo de gosto pessoal)." Aliás, mais tarde, ele se aplicaria em frisar, no Conta Corrente, essa mesma predileção.

Estudiosos já sondaram a presença de Ramos Rosa na obra de Vergílio e vice-versa, e vislumbraram uma íntima cumplicidade entre romancista e poeta, numa verdadeira conversa entre textos. Luís Mourão, por exemplo, lê o romance de Vergílio, Em Nome Da Terra, através de O Não E O Sim do poeta, ambos publicados em 1990 (MOURÃO, 2001, p. 15-22). Tanto Vergílio quanto Ramos Rosa, a crer no ensaísta, teriam percorrido os seus próprios "passos místicos" que, por pura convicçáo, se desviavam igual e coincidentemente de quaisquer laivos divinos. Ana Paula Coutinho Mendes também lidou com essa contigüidade e pontua que cada um deles representava, para o outro, uma espécie de "horizonte ou estímulo de escrita", ancorado numa "atração mútua pelo discurso da Filosofia". Em escritos de Vergílio sobre Rosa ou de Rosa sobre Vergílio fica evidente que cada qual reflete, em última análise, a si próprio

\footnotetext{
* Professora Titular de Literatura Portuguesa da Universidade Federal de Sergipe - UFSE e pesquisadora do CNPq.

${ }^{1}$ As trinta e quatro cartas de Vergílio Ferreira a mim endereçadas foram depositadas nos reservados da Universidade de Évora, no Centro de Estudos em homenagem ao romancista que, nessa cidade, foi, durante largo tempo, professor.
} 
e escreve sobre si mesmo na medida em que reconhece a obra e os ditames estético-filosóficos do respectivo amigo (COUTINHO, 2005, 275-291).

Sobre Vergílio e Herberto, no entanto, o que me consta é que este assinou e dedicou pessoalmente ao romancista cerca de treze dos volumes da sua obra, como se pode constatar pelo espólio depositado na Biblioteca Nacional de Lisboa. Os mais antigos registros datam de 1961, que são os de Poemacto e de $A$ Colher na Boca, muito embora O Amor em Visita, obra inaugural de Herberto, lançada em 1958, também esteja presente no acervo de Vergílio, mas com anotaçáo de 1974 e, como as outras, ostentando uma dedicatória do poeta. O que indicia, da parte de Herberto, um contínuo apreço ao romancista que, por sua vez, teria tomado contato com a poesia dele pelo menos desde que Ramos Rosa, também seu companheiro de tertúlias, lhe consagrara um estudo em julho de 1961. Trata-se do texto "Poeta Órfico", publicado no Diário de Lisboa e, no ano seguinte, no livro Poesia, Liberdade Livre, de Ramos Rosa. Não esquecer que Ramos Rosa e Herberto se frequentavam, pelo menos até o final da década de 70.

No entanto, em Conta Corrente, Vergílio se declara desencantado com Herberto logo após o 25 de Abril, a quem, como assegura ali, considerava de fato o maior poeta do seu tempo "logo a seguir ao Ramos Rosa". Ele supóe entáo, com certa ingenuidade ou malícia, que Herberto tenha deixado crescer a barba para encampar o tipo oficial dos camaradas do Partido Comunista Português que, aliás, na altura, e muito contrariamente ao que especula Vergílio, Herberto desbancava em carta. ${ }^{2}$

Vergílio era atacado deveras por tal gênero de fantasias quando se tratava da dita "esquerda" que, segundo se ressentia, lhe havia desferido profundos e injustos golpes. E acabava se maltratando e se atormentando com suposiçôes políticas equivocadas que dum momento para outro se convertiam em paixão exacerbada e cega ou então em muxoxos ranzinzas, dos quais não escapavam nem mesmo os amigos mais próximos Eduardo Lourenço incluído. Aliás, o temperamento constante de Vergílio é dotado de uma susceptibilidade sempre alerta, de repente arrepiada e irascível por qualquer pequena sombra de desconfiança que sinta pairar sobre a sua pessoa.

$\mathrm{Na}$ sua correspondência com Jorge de Sena, o nosso romancista náo se intimida, em agosto de 1964, em revelar-se muito desgostoso e melindrado com o poeta exilado no Brasil. E tal ocorre simplesmente porque levara a sério (e de modo exaltado) um burburinho maledicente em que constava ter Sena afiançado ser Vergílio um escritor "medíocre" - fato que este situa nas tramas de "uma conjura" que se teria montado contra ele "através da querela do defunto 'neo-realismo". Sena, em contrapartida, o redargui interrogando (atônito) se também ele "vai deixar que o lixo o submerja" (VERGÍlIO/SENA, 1987, p.90). Tal argumento parece ter sido sensível a Vergílio, ao

\footnotetext{
${ }^{2}$ Carta a mim dirigida e datada de 27/07/1975. O espólio das cinquenta e duas peças de Herberto Helder a mim endereçadas foi depositado nos reservados da Universidade da Madeira, pois que se destinam aos guardados em vias de fundar a Cátedra Internacional Herberto Helder, pertencente ao Centro de Investigaçáo em Estudos Regionais e Locais da mesma Universidade.
} 
que tudo indica, pois que o devolve a si mesmo a ponto de se desculpar com o correspondente.

Não é o caso, agora, de defender de tais acusações injustificadas o Herberto (também ele desiludido com o $\mathrm{PCP}$, conforme me relata nessa epistolografia de então, apodando ao Partido de "estalinista") ${ }^{3}$, mas tão somente de conjecturar sobre alguns encontros - talvez fortuitos e em registros muito diversos - entre uma e outra obra. Penso, para o caso, e já que sou leitora assídua de ambos, numa das peças de Os Passos Em Volta (1963), em que o narrador nos explica, em primeira pessoa, como adquiriu o seu "Estilo" - esse o título do conto que, aliás, abre o volume.

Segundo sua explanação, o problema urgente da existência, a "desordem estuporada da vida", nos obrigaria, diante de experiências torturantes e contínuas, transbordadas sobretudo em noites vazias e sem remissão, a buscar um jeito para poder suportar o peso de tal evidência. Infelizmente, nenhum recurso válido é oferecido, seja pelo médico de plantão (que só pode lhe receitar "barbitúricos"), seja pela lição alheia. Há gente, por exemplo, que cultiva orquídeas e que se salva por essa via. Mas esse não é o caso do nosso narrador, que se póe em campo para encontrar um específico "estilo" a fim de não dar "em pantanas".

Nessa cruzada, ele ouve Bach e pratica matemática - descobrindo a parecença entre a música e as equaçôes a incógnitas que ele se póe a resolver nas insônias. Tais exercícios o nutrem de certo fôlego para enfrentar o terror noturno quando "as grandes sombras incompreensíveis" erguem-se no meio do quarto, quando "a imensa melancolia do mundo parece subir do sangue com a sua voz obscura." (HELDER, 1985, p.712) Todavia, o que verdadeiramente o acode e o socorre é o "processo de esvaziar as palavras".

Ou seja: o narrador toma uma palavra "fundamental" - não por acaso "Amor, Doença, Medo, Morte, Metamorfose". Depois, passa a articulá-la em voz baixa, uma, duas, três - vinte vezes! Ao fim desse processo, esclarece-nos ele, a palavra resulta como que desencarnada do seu significado, tornada alheia, sem sentido, de modo que lhe é possível apropriar-se dela à vontade. Essa é, segundo o narrador, uma das maneiras de obtenção do estilo, meio eficaz de se safar da loucura, da "tenebrosa loucura": meio de conquistar "aquela maneira subtil de transferir a confusão e violência da vida para o plano mental de uma unidade de significação".

Ora, como nos evidencia o autor, a escrita da poesia é uma aquisição semelhante, do mesmo naipe - é uma maneira de "estilo". E isso porque, na Arte, o poeta se livra das contingências, delegando-as às criaturas que a habitam e que nela são criadas. Assim, se no seu poema "Elegia Múltipla VI" de A Colher Na Boca (que Herberto cita nesse conto), as crianças enlouquecem, são elas, as "crianças", que perdem a consciência - e não o poeta! E se isso se dá é porque, afinal, elas é que não conseguiram descobrir o seu próprio... estilo!

${ }^{3}$ Na mesma carta de 27/07/1975 a mim dirigida. 
Acontece que, malgrado a posse desse tal "estilo" (que, em contrapartida, pode nos encher desgraçada e desastrosamente de "parcimónia"...), nunca se deve abdicar da verdadeira insanidade, daquela tão "tenebrosa e maravilhosa loucura" - essa sim mais condizente com a nobreza e com "o segredo da nossa humanidade". De modo que, muito embora o poeta se esforce por discernir para si um esquema, um teorema de apaziguamento que the conceda enfrentar os avessos e desencontros da vida, evitando naufragar na desmesura e no desvario - ele, sem tal poderoso combustível, jamais produzirá coisa alguma digna da sua condição de homem.

O conto, logo se vê, prima-se pelo paradoxal. Por um lado, fornece o aceno para se buscar a notável equação capaz de redimir o homem da dor, do tormento e da alucinaçấo, sem, no entanto, fazê-lo abandonar a estima pela "loucura", aquela que nos salva da mediocridade e da bitola social.

De um ponto-de-vista, creio que essa peça de Os Passos Em Volta esclarece o caminho trilhado pela própria poesia de Herberto Helder, a sua maneira rigorosa de dizer o arbitrário, suas obliqüidades e descontínuos, seu modus rimbaudiano de tornar a "alma monstruosa" - enfim, a sua prática poética de "assassino assimétrico", tal como ele mesmo se denomina em Retrato em Movimento (1968).

Não esquecer, por exemplo, que, em $O$ Bebedor Nocturno (que também é do mesmo ano), tal "estilo" de esvaziamento das palavras é cultivado como maneira de "traduçáo" poética. Herberto refere aí essa habilidade de pegar da palavra e vertê-la para quinze línguas diferentes. Tal ocupação acaba dotando o significado de uma velocidade impossível, transformando a "coisa", que a palavra era, em uma "colorida e abstracta proliferaçáo sonora", que, assim transubstanciada, vai viver em permanente "estado de Babel".

Na mesma linhagem do poeta de "Estilo", o poliglota de Herberto é então concebido:

o seu pensamento, partindo do hebraico, dá um salto quase místico no latim e cai de cabeça para baixo no grego antigo. (...) Faz disparates destes: verte de nauatle para esquimó, emocionando-se em banto e pensando em chinês, um texto que o interessou por qualquer ressonância árabe. (HELDER, 1968.)

Esse processo aparentemente ingênuo de "estilo" pode, pois, deitar alguma luz não só sobre a linhagem das suas "versões" como também sobre da concepção de sua própria poética.

O bizarro é, quanto a Vergílio, que em Aparição (1959), há como que uma exposição dramática e à flor da pele dessa mesma contradiçáo encontrada em Herberto que, aliás, também alimenta o filme Teorema, de Pier Paolo Pasolini (1968). Chama a atençáo que o título da obra do extraordinário diretor italiano, sendo posterior à de Herberto, possua uma acepçáo táo semelhante à que este faz transitar no seu conto, e pergunto (já agora) a que incógnita!

Em lugar do comedimento e da circunspecção doados pela prática de um "estilo", o que se vê em Vergílio e Pasolini é o desregramento e o desvario ditados pela 
descoberta da ausência de razoamento da vida. Seja numa dimensão filosófica que, no entanto, traz seqüelas graves e palpáveis, como ocorre em Aparição, seja em termos morais, quebrando tabus, como acontece em Teorema. A presença de um estranho que penetra num ambiente familiar burguês descerrando e praticando valores que submergiam escorados na sombra e na mudez, passa a decretar, da parte das pessoas concernidas, comportamentos díspares, desencontrados e inesperados, que afetam sobremaneira as suas relaçóes pessoais e sociais, alçando-as a um absurdo paroxismo.

Em Aparição, é o ingresso de Alberto Soares como professor na sociedade tradicionalista de Évora que, com suas inquietaçôes metafísicas, desencadeia uma reviravolta nos bens éticos e culturais, bem como um atordoamento de direçôes, incluindo patéticas fatalidades. Diante do flagrante, da evidência sem remissão da morte, Alberto sente a necessidade de incorporá-la à plenitude da vida, e essa mensagem, tão óbvia e ao mesmo tempo tão inocente e meritória, há de desarvorar as pessoas a sua volta.

Assim, no diapasão vergiliano que, para o caso, é muito semelhante ao do narrador de "Estilo", Alberto constata que a certeza da vida que em nós se asila acaba por nos despertar abruptamente, ao mesmo tempo em que nos assusta e nos atordoa. Trata-se mesmo de um "vulcão brutal que sai de nós, o jacto do deus que nos habita", uma espécie de "monstruosidade que nos adormecia dentro" (p.72). Ora, no intuito de conviver com tal atrocidade, faz-se necessário, para usar em Vergílio a nomenclatura de Herberto, enfrentar essa "desordem estuporada", ou, no registro de Vergílio, "justificar a vida em face da inverosimilhança da morte" (p.49) - o que obriga tais personagens a inaugurarem o seu próprio "estilo".

Interessa-me aqui, particularmente, a maneira como Carolino, vulgo Bexiguinha, monta a sua equação, o seu teorema diante dessa "aparição" - como descobre o seu estilo. Botando-se no centro de si mesmo, crê Carolino que pode ver-se e sentir-se "de dentro para fora", e que, desse modo poderá descobrir "a pessoa" que está em si - a pessoa que é ele. Confessando ao professor Alberto tal experiência, Carolino relata, então, o exercício que pratica para saber-se. E qual é ele?! O de "mastigar as palavras"! E repare-se, na justificativa de Carolino para Alberto, a semelhança de concepção de método, a perspectiva muito próxima à do poeta de "Estilo".

Explica o jovem aluno ao professor:

- Bem... É assim: a gente diz, por exemplo, pedra, madeira, estrelas ou qualquer coisa assim. E repete: pedra, pedra, pedra. Muitas vezes. E depois, pedra já não quer dizer nada. (p.78)

Carolino, no entanto, acabará por se enveredar na sedução da "loucura" e cair nas suas malhas - bem ao contrário do poeta de Herberto Helder que, encontrando um estilo mais produtivo, será capaz de coabitar com ela. No caso de Vergílio, há como um descambar para a desregração da consciência, que culmina com uma perda total do instinto de civilidade, de fraternidade, na experimentação de um egocentrismo agudizado, coroado pelo ato de assassinato. Em Herberto, o personagem-narrador descobre 
produtivamente a poesia e a criação artística, muito embora não deixe de conviver (saudavelmente?) com a desmesura.

É possível supor, numa hipótese ousada (apenas para aproximarmos os dois autores), que esse método pode também estar na base da formulação da personagem Cristina de Aparição. Delineio tal proposiçáo porque creio que os personagens ao redor de Cristina vêem nela justo essa possibilidade: a de "salvaçẫo" (por mais fortuita que seja) através da arte. De resto, a interpretaçáo que ela confere às peças que toca ao piano permite que eles comunguem em Cristina a mais alta sensação estética - a da visão, do flagrante de algo que, nessas circunstâncias, "abusa" dela e a ultrapassa, elevando os seus espectadores a um clímax impossível de evidência da vida e da morte - a que Vergílio chamará de "aparição", e que, em outro registro, busquei entender como semelhante à "aura" definida por Walter Benjamin. ${ }^{4}$

Nesse contexto, o torto caminho de Carolino terá sido o de ter concluído que, se já não há mais deuses para criarem, o homem é quem deve ocupar esse posto vacante, ainda que proceda ao contrário, destruindo. Aliás, bem sabemos, essa é uma das versóes flexionadas por certa "insanidade" desocultada pelos Existencialismos, e bem ilustrada em alguns personagens de Sartre, por exemplo, cuja linhagem parece inspirada em Dostoievsky. Como o homem não pode criar (e essa é a imensa diferença entre o personagem de Vergílio e o de Herberto), ele pode, no entanto, matar - o que seria um gesto táo poderoso quanto o do Todo Poderoso. De modo que Carolino se transforma em "deus" através da patética morte que impóe à Sofia. Assassinando-a, ele supóe recuperar para si (canibalisticamente) o poder que ela detinha, a grandiosidade do que ela era, a sua magnitude. Matando-a, ele se alça a uma altura que a transcende! E é assim que tal método acaba por destruí-lo, em lugar de redimi-lo.

Mas o curioso nessa aproximação entre ambos os autores é que o processo descrito nas duas obras, buscando para o absurdo da vida e da morte uma solução - é exatamente o mesmo: o de esvaziar as palavras, o de mastigar as palavras, o de perscrutar aquilo que as palavras ignoram a respeito do oculto que nos habita! No entanto, se é possível aqui a hipótese de compreensão catártica da arte (e aplicando a Vergílio a equação de Herberto), poderíamos cogitar que Carolino realiza para Vergílio uma das suas próprias maneiras de lidar com a loucura, tal como Herberto as realiza em seu poeta-narrador.

Um outro componente que surpreendo tanto em Vergílio quanto em Herberto diz respeito ao uso desportista da... "bicicleta". Em Herberto, esse meio de locomoçáo busca dar familiaridade a uma perscrutação espacial e semântica completamente desprovida de perspectivas e de módulos referenciais - a esmo, desorientada e vagante: errante. Ou seja: a bicicleta em Herberto é a maneira de o poeta demonstrar que náo pilota uma bike, que é ela quem o dirige e maneja o poema para avançar pela lua, pelos satélites, pela memória, pela neve - pelo nome:

${ }^{4}$ Remeto ao meu texto "A nostalgia da aura", In Memoriam de Vergílio Ferreira (org. Maria Joaquina Nobre Júlio). Lisboa: Bertrand Editora, 2003, pp. 168-178. 


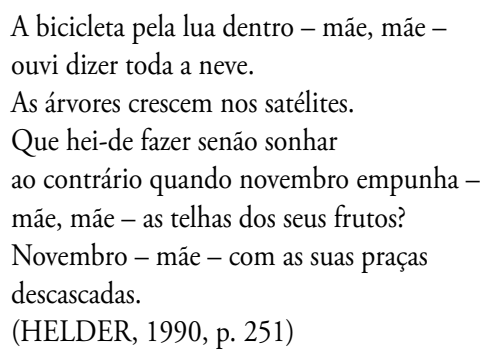

Num processo combinatório ao gosto de A Máquina De Emaranhar Paisagens (1964), de Comunicaçāo Académica (1965), este poema de Electronicolírica (1964), nascido sob a égide de sua versão anterior em A Máquina Lírica (1963) - utiliza, como elucida o próprio Herberto, "um limitado número de expressóes e palavras mestras", a fim de promover "a sua transferência ao longo de cada poema". Sublinho que os textos desse livro são produzidos graças a signos submetidos a uma dissolução semântica que ocorre por meio de um jogo de permutaçóes entre tais elementos constitutivos. Ou, como me explicaria o próprio Herberto em carta, o livro utiliza

vários planos imagéticos e vocabulares simultâneos, reiteração verbal, constituição de diversos centros de percepção visual: mas, repara, cada poema possui um centro fundamental, e toda a matéria que o forma reflui para esse centro, depois de se desdobrar. ${ }^{5}$

Ora, voltando aos termos do narrador de "Estilo" ou aos do Carolino de Aparição, trata-se, de novo, do processo de esvaziamento de palavras, do processo de mastigação delas. O fito do poeta de Electronicolírica é, de novo, fazer as palavras perderem o seu significado, deixar vagar nelas o significante em busca de um novo sentido.

E é assim que, depois de a "bicicleta" de Herberto percorrer ao léu grandes espaços de significantes alheios, inusitados e dissonantes, ela acabe se vergando ao peso desculturalizado! - de um "grande atum negro". De maneira que um outro e inaugural significado nasce cavalgando o significante "bicicleta", depois de esta errar pelas distâncias entre palavras, versos, estrofes, exibindo saltos de obstáculos pelos planetas e pela memória (no transcorrer das veredas selvagens do poema). E esse novo significado, atingido pelo esvaziamento do significante, torna-se, de fato, absolutamente insólito e imperscrutável: ora, a "bicicleta" se transforma nesse grande e negro "peixe". Curioso como a imagem de "um grande atum negro" pilotando uma "bicicleta" nos remete de imediato a um Hieronymus Bosch da palavra. E a um Bosch táo contemporâneo!

Dessa forma, tal como o constata já um outro poema intitulado decidicamente "Bicicleta" (e que está em Quatro Cançôes Lacunares que, em 1965, eram Cinco) - lá "vai [deveras] a bicicleta do poeta em direcção/ao símbolo", em direção "aos seus sinais":

${ }_{5}^{5}$ Carta a mim dirigida, datada de 04/08/1979. 


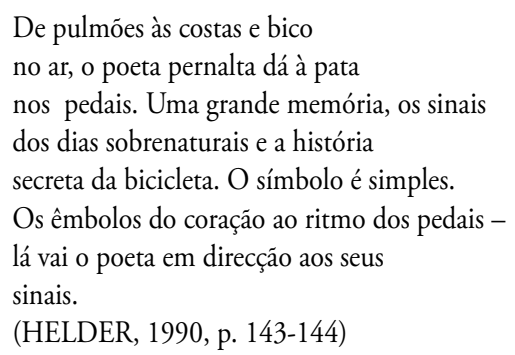

Já em Vergílio, a "bicicleta" não é índice dessa velocidade que adquire em Herberto, vertigem que vai triturando e modificando o significado. Ao contrário, é movimento sim, mas muito mais um bulício interno, de rememoração e de reinvenção, muito mais vagar, mergulho lento na paisagem e na memória - morosidade que vai colocar, em Para Sempre (1983), Alexandra contra Paulo.

A jornalista Xana, enquanto representante da contemporaneidade, há de praticar a bicicleta, então, como o símbolo que a distancia do seu pai (Paulo), arqueado, segundo ela, sob o peso do passado. Este é bibliotecário e, ao mesmo tempo, narrador do romance em pauta e também alvo da virulência jocosa e das chacotas da filha modernosa, que se dizia pertencer a outro universo cultural, mental e temporal que náo o dele. No dela, há pressa, há urgência. No de Paulo (via Xana), há apenas excessivo deambular - e a bicicleta o metaforiza.

Só que a preponderância desse exercício moroso em Vergílio Ferreira dá-se como mola para as verrumaçóes estéticas e humanistas que caracterizam o teor pessoal e único do seu romance lírico-problemático. Como propõe Luís Mouráo, se de fato há alguma "velocidade" em toda a obra do Vergílio, esta se deve antes a uma "metafísica dos meios de transporte". Em Para Sempre, a "bicicleta" é a "emblemática do andamento silencioso e despojado", que funciona como um modo específico de conhecimento das coisas e do mundo. (MOURÃO, 2001, p. 43)

Para Xana, no entanto, a bike do pai não passa de uma versão do... carro-de-bois! Ela se crê (supondo-se muito diferente dele) representante de um mundo "revolucionário", do presente e do agora, que empunha como garantia de realidade o "gravador" e aquilo que este relata e comprova. Essa técnica substitui o lugar do testemunho mobilizado pela memória meritória que o perpetua, e da qual se vale o narrador de Para Sempre, assim como o emissor das Cartas a Sandra (1996) - o mesmo Paulo bibliotecário, o frisado pai de Alexandra.

Enquanto Paulo deplora intimamente em Xana um ar "fadista" de desleixo e displicência, assumido por ela no agito de trabalhar, como jornalista, em algum inquérito ou reportagem, ela o acusa caricata e risivelmente de "múmia", de recender "a mofo", de ter a alma em "in-fólio", de expor uma "vida trabalhada a traça e a bafio". E isso porque a filha acredita que a escrita do pai nasça do hermetismo dum gabinete tumular, rodeado de quadros e de livros, de estantes que não passam de cadáveres "em 
jazigo", onde ele, sequer, pode-se dar conta do que ocorre para além das paredes que o fecham. O tempo do livro, ao qual o pai se dedica, escrevendo ou trabalhando, é, para ela, "o tempo da morte", do "candeeiro de petróleo", "do óleo de fígado de bacalhau", "dos botins, das cuias, dos palitos", das "perucas, das lamparinas e dos penicos". Contrariamente, os "modernos" (segundo Xana - os seus pares) estấo "vivos e cheios de coisas a fazer. O tempo do livro é o da imaginação trabalhosa e nós estamos cheios de realidade. (...) O tempo do livro é o do carro de bois". (FERREIRA, 1983, p. 107-108)

Como busco ressaltar, do ponto de vista de Alexandra, o que Paulo produz não vai além de uma atividade ultrapassada, emanada do domínio do arcaico, do que saiu fora de circulação e do que não mais interessa, pois que caducou. O universo do pai é um inútil demodé. Paulo representa o que a sociedade refugou, o que se situa no estágio antigo do artesanato relegado hoje às traças, ao tempo dos vagares, e está em definitivo sepultado no magnífico monumento-mausoléu que o representa: a Biblioteca. Em compensaçáa, para Xana (e ela se ufana disso), escrever

É diferente. Escreve-se um artigo como se toma um café. As pessoas lêem e deitam fora. Se alguém o apanha, é para uma necessidade de momento. Para embrulhar castanhas. Para utilizar na retrete, quando não há papel. (FERREIRA, 1983, p.106)

O que ela realiza tem sempre como fito uma necessidade instantânea, fortuita, logo substituída por outra, índice do sinal fluido e líquido da modernidade. E não é nem um pouco pejorativo, para ela, que o uso do jornal, mesmo quando reduzido apenas a papel, faça parte da latrina ou do lixo. Tudo nela diz respeito ao "momento", ao que se usa e se joga fora - ao consumo. A sua geração é a "contemporânea", visto que se move pela agilidade do pensamento, em ritmo de pressa para acompanhar o compasso dos tempos que seguem, em que a palavra nada retém do sagrado que um dia a prodigalizou. Ocorre que Xana náo se dá conta de que, praticando esse ritmo de "bicicleta", o pai escreve da maneira a mais "contemporânea" possível!

Em Vergílio, a situação do narrador é quase imóvel, porque ele sempre se encontra, no presente, em estado de rememoraçáo e de escrita. Lembro que ele se acha, por exemplo, "num quarto nu" (em Manhã Submersa), numa "sala vazia" (em Aparição), numa "cela de prisão" (em Estrela Polar e em Nitido Nulo), na aldeia vazia (em Alegria Breve), na casa vazia da infância (em Para Sempre e em Cartas A Sandra), num "Lar" (em Em Nome Da Terra) e assim por diante. É a posição solitária de ensimesmamento, de aparente paralisia física, temporal e espacial que lhe propicia a mistura (quase imperceptível e, em seguida, progressivamente indiscernível) do presente e do passado relembrado (e mesmo de um futuro a projetar-se), graças à comoção que a revivescência provoca sobre a escrita, mercê das conseqüentes distorçóes que a narrativa acaba exercendo sobre o discurso. Esse encontro de escritas produz aquilo a que chamei (em 1973) de "intersecção entre discurso e narrativa" - de "escritura". E creio que vem daí - para definitivamente polemizar com Xana! - o caráter invulgar e vanguardista da escrita de Paulo, figuração do próprio modus vergiliano. 
Vergílio Ferreira é o responsável, no moderno romance português, pela adoção inovadora e atualizadora (em prosa) daquilo que Fernando Pessoa supôs e executou em verso - da sua lição de "estilo" - da sua "chuva oblíqua", ou seja, do "interseccionismo". E, nesse sentido, a escrita de Vergílio ganha uma dimensão supersônica - quebra a barreira do sentido. A bem da verdade, nem sei dizer que tipo de jato Vergílio pilota entấo. Um "mirage"? Uma miragem, um milagre!

E uma solidáo angustiante - como pude admitir que me esperassem? - sufoca-me quando chego à cidade. Subitamente, na noite imensa. Tráfego cego, submerso, como periscópios as luzes, traçam à superfície as linhas, o emaranhado da sua procura. Os reclamos luminosos no ar crepitam, fazem sinais à noite, fazem sinais ao silêncio, cintilam no mar, miríades de partículas de sol. Ouço a música ainda ouço-a ainda? para lá das arribas marcando o ritmo da ondas, balanceando na noite e a minha solidáo. Como a obsessiva memória do que nos feriu, cresce, independente, vem à superfície, mergulhamo-la à força, vem à superfície como um pedaço de cortiça. Por fim resigno-me vou com ela pelas ruas atrás de mim como um cão - o cão desapareceu no extremo da praia. (FERREIRA, 1971, p. 71-72)

Em Photomaton \& Vox (1979), Herberto nos esclarece que essa idéia da "bicicleta" já estava, há séculos, em Fra Angelico. Na Anunciação, o Arcanjo São Gabriel deveras dirige uma bike: como náo se vê, o fato de pedir desculpas com muitas cores (em azul, ouro e prata), mostra que o pintor está manipulando a metáfora das asas nas costas do anjo para o anúncio da gravidez de Maria, ou seja, para a "subversão da natureza”. Segundo Herberto, foi preciso decifrar completamente essa metáfora para inventar a... bicicleta!

Não esquecer que, muito tempo depois (em Hollywood), Marilyn Monroe haveria de assegurar que é de cima de uma... bicicleta, que se pode ver melhor a natureza! Marilyn procede tal e qual o poeta de Herberto que, por sua vez, da bike passará para o skate, e deste, atravessando já convicçóes motociclistas e automobilísticas, irá desembocar no tráfego aéreo verticalizado. E tudo isso num enorme esforço de "contemplar" a natureza, de capturá-la. Ah, o "estilo"! (HELDER, 1979, "motocicletas da anunciação" p. 110-112 e "a paisagem é um ponto de vista" p. 63-71) ${ }^{6}$

Vê-se, pois que, nesse rumo, Herberto acaba saltando da "bicicleta" para o helicóptero - na verdade para um dispositivo comandado por Rimbaud, um herbertiniano "helicoptère ivre". Afinal, convenhamos, é preciso usar uma máquina adequada ao aprisionamento contemporâneo de um real a cada dia mais arisco!

Assim, no afẫ de atualizar esse grande inventor da visão abissal, tornou-se urgente, para Herberto, substituir o tal "bâteau" por essa estonteante máquina. Herberto pilota entáo um helicóptero que tende a tornar-se ainda mais eficaz e poderoso quanto mais "bêbado" estiver!

\footnotetext{
${ }^{6} \mathrm{O}$ texto do Marilyn, foi publicado antes com o título "Declaram que..." no Nova 1 (Magazine de Poesia e Desenho). Lisboa: Jornal do Fundão, inverno 1975-1976.
} 
Digamos, já agora para concluir, que a mesma bike providenciou destino diverso a seus dois usuários. De um lado, conduziu Vergílio ao mirage supersônico que presenciamos; de outro, transportou Herberto ao mais embriagado dos helicópteros! E observe-se se não é mesmo disso que se trata:

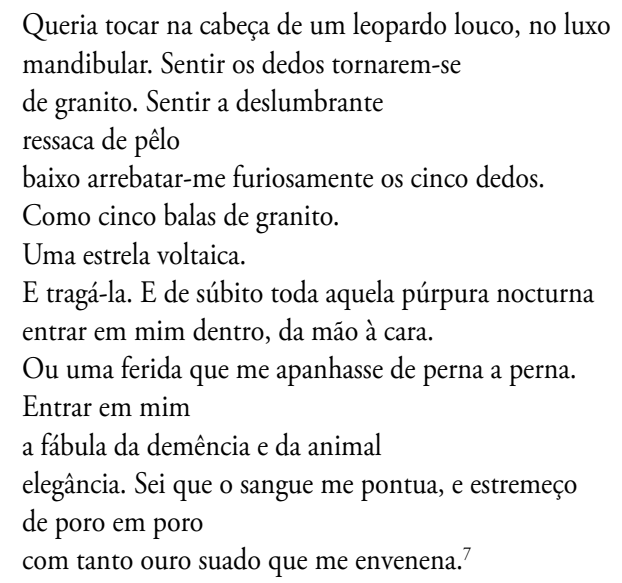

\section{REFERÊNCIAS}

FERREIRA, Vergílio. Nitido Nulo. Lisboa: Portugália, 1971. , Vergílio. Para sempre. São Paulo: Difel, 1983.

\& SENA, Jorge de. Correspondência (Org. e notas de Mécia de Sena, intr. Vergílio Ferreira). Lisboa: INCM, 1987, p. 86.

HELDER, Herberto. O Bebedor Nocturno. Lisboa: Portugália, março de 1968. . Photomaton \& Vox. Lisboa: Assírio \& Alvim, 1979.

. Estilo. Os Passos Em Volta. Lisboa: Assírio \& Alvim, 1985, p. 7-12.

. A bicicleta pela lua dentro - máe, mãe -. A Máquina Lírica. Poesia Toda. Lisboa: Assírio \& Alvim, 1990, p. 251-254.

JÚLIO, Maria Joaquina Nobre (Org.). In Memoriam de Vergílio Ferreira Lisboa: Bertrand, 2003.

MENDES, Ana Paula Coutinho - Vergílio Ferreira e António Ramos Rosa: o encontro entre o romancista e o poeta. Revista da Faculdade de Letras - Linguas e Literaturas, II Série, vol. XXII, Porto, 2005, pp. 271-290.

MOURÃO, Luís. Em Nome da Terra ou O não e o sim. Vergílio Ferreira: Excesso, Escassez, Resto. Braga: Angelus Novus, 2001, p. 15-22.

7 Abro a esmo o Ofício Cantante. Poesia Completa, de Herberto Helder. Lisboa: Assírio \& Alvim, janeiro de 2009, p. 358. O poema pertence a Flash e náo tem título. 